\title{
Achieving a High-Strength CoCrFeNiCu High-Entropy Alloy with an Ultrafine-Grained Structure via Friction Stir Processing
}

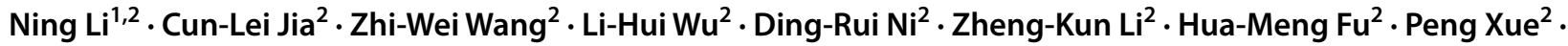 \\ Bo-Lv Xiao ${ }^{2} \cdot$ Zong-Yi Ma ${ }^{2} \cdot$ Yi Shao $^{1} \cdot$ Yun-Long Chang ${ }^{1}$
}

Received: 10 December 2019 / Revised: 7 January 2020 / Published online: 9 April 2020

(c) The Chinese Society for Metals (CSM) and Springer-Verlag GmbH Germany, part of Springer Nature 2020

\begin{abstract}
High-entropy alloys (HEAs) are a new class of materials with a potential engineering application, but how to obtain ultrafine or nano-sized crystal structures of HEAs has been a challenge. Here, we first presented an equiatomic $\mathrm{CoCrFeNiCu} \mathrm{HEA}$ with excellent mechanical properties obtained via friction stir processing (FSP). After FSP, the Cu element segregation in the cast $\mathrm{CoCrFeNiCu} \mathrm{HEA}$ was almost eliminated, and the cast coarse two-phase structure (several micrometers) was changed into an ultrafine-grained single-phase structure $(150 \mathrm{~nm})$ with a large fraction of high-angle grain boundaries and nanoscale deformation twins. This unique microstructure was mainly attributed to the severe plastic deformation during FSP, and the sluggish diffusion effect in dynamics and the lattice distortion effect in crystallography for HEAs. Furthermore, FSP largely improved the hardness and yield strength of the CoCrFeNiCu HEA with a value of $380 \mathrm{HV}$ and more than $1150 \mathrm{MPa}$, respectively, which were $>1.5$ times higher than those of the base material. The great strengthening after FSP was mainly attributed to the significant grain refinement with large lattice distortion and nano-twins. This study provides a new method to largely refine the microstructure and improve the strength of cast $\mathrm{CoCrFeNiCu} \mathrm{HEAs}$.
\end{abstract}

Keywords Friction stir processing $\cdot$ High entropy alloys $\cdot$ Strengthening $\cdot$ Ultrafine grains $\cdot$ Microstructure

\section{Introduction}

High-entropy alloys (HEAs) are metal materials with a solid solution structure, which normally consist of five or more elements with similar molar mass [1]. Different with traditional metals, four characteristics have been revealed for HEAs, which are high-entropy effect in thermodynamics, lattice distortion effect in crystallography, sluggish diffusion effect in dynamics and "cocktail" effect [2]. HEAs have developed in recent years, because they show excellent

Available online at http://link.springer.com/journal/40195.

$$
\begin{aligned}
& \text { Li-Hui Wu } \\
& \text { lhwu@imr.ac.cn } \\
& \text { Yun-Long Chang } \\
& \text { sychyl@126.com }
\end{aligned}
$$

1 School of Material Science and Engineering, Shenyang University of Technology, Shenyang 110870, China

2 Shenyang National Laboratory for Materials Science, Institute of Metal Research, Chinese Academy of Sciences, 72 Wenhua Road, Shenyang 110016, China high-temperature stability and mechanical properties including yield strength, creep properties, fracture toughness, etc. [3-5]. Therefore, HEAs exhibit extensive application prospects in many industrial fields, such as application as biological materials, superconducting materials, hydrogen storage materials, etc.

As is well-known that fine- or ultrafine-grained structures result in a high strength in metals, thus, in order to obtain high-strength HEAs, researchers have used severe plastic deformation (SPD) methods, such as equal-channel angular pressing (ECAP), high-pressure torsion (HPT), dynamic plastic deformation (DPD), to refine the HEAs [6-8]. However, the materials processed by these SPD methods generally exhibit a low plasticity although a high strength could exist. Also, a limit-sized processed sample is generally obtained, but large bulk samples are very difficult to be obtained by these SPD methods. Thus, the development and application of the fine- or ultrafine-grained HEAs are largely limited [9-11].

Friction stir processing (FSP) [12-15], as a variation of the friction stir welding (FSW) technique, has been used for modifying the microstructure and mechanical properties 
of $\mathrm{Al}, \mathrm{Mg}$, Ti alloys etc. [16-28], recently applied for the HEAs [29, 30]. The basic principle of FSP is as follows. A high-speed rotated tool is inserted into the workpiece, and the large friction heat between the rotated tool and the workpiece is generated, resulting the softening of the material. The softened material then experiences severe plastic deformation and recrystallization due to the pressure of the shoulder and the stirring effect of the pin. As a result, the fine and uniform microstructure could be obtained $[17,18]$. Different from other SPD methods, FSP can produce fine or ultrafine-equiaxed-grained structures with low dislocation density and a high fraction of high-angle grain boundaries $[17,18,31]$. In addition, FSP can produce bulk materials and eliminate the casting defects. Besides, FSP is a SPD processing method with a very short process. Therefore, FSP shows a great potential in modifying the microstructure and properties of the HEAs.

So far, FSP has been reported to improve the strength of HEAs [29, 30, 32, 33]. For example, FSP was used for the local modification of $\mathrm{Fe}_{40} \mathrm{Mn}_{20} \mathrm{Co}_{20} \mathrm{Cr}_{15} \mathrm{Si}_{15}$ alloy, and a good comprehensive mechanical property with high strength and toughness was achieved in the stir zone (SZ) by Nene et al. [29]. Komarasamy et al. [30] reported that the yield strength increased by three times after grain refinement, while maintaining a large uniform elongation of face-centered cubic (FCC) $\mathrm{Al}_{0.1} \mathrm{CoCrFeNi}$ alloy via FSP. In addition, the $\mathrm{CoCrFeNiAl}_{0.3} \mathrm{HEA}$ was successfully welded without welding defects using FSW by Zhu et al. [32]. Also, Zhu et al. [33] explained the recrystallization mechanism of the $\mathrm{Co}_{16} \mathrm{Cr}_{28} \mathrm{Fe}_{28} \mathrm{Ni}_{28}$ HEA during FSW. However, all the studies above mainly focused on $\mathrm{CoCrFeNiAl}$ and $\mathrm{CoCrFeN}$ iMn HEAs, other HEAs, such as the typical HEA material, $\mathrm{CoCrFeNiCu}$ alloy have not been conducted by FSP so far.

In recent years, some researchers have also carried out relevant researches on the $\mathrm{CoCrFeNiCu} \mathrm{HEA}[34,35]$. For example, Zhang et al. [35] found that the $\mathrm{CoCrFeNiCu}$ alloy as coating material has an excellent thermal stability, and no phase transformations occurred up to $1000{ }^{\circ} \mathrm{C}$, but the relevant mechanical properties had not been reported. Oh et al. [34] found that the yield strength (YS) of 265-960 MPa was obtained after cold rolling, but the microstructure-property relationship was lacked. Furthermore, at present, the $\mathrm{CoCrFeNiCu}$ alloy is still mostly studied or used at a casting state, which also exhibits most of the shortcomings of the castings, such as casting porosities, element segregation, coarse microstructure, low strength and ductility. Therefore, a strength-ductility enhancement on the $\mathrm{CoCrFeNiCu}$ alloy using a simple processing method is highly demanded.

Based on the unique characteristics of FSP, in this study, we used FSP applied to a $\mathrm{CoCrFeNiCu}$ alloy for the first time. The aim is to: (a) explore the feasibility of FSP applied to CoCr$\mathrm{FeNiCu} \mathrm{HEAs}$, (b) probe into the possibility of obtaining an improved property of HEAs and (c) discuss the relationship of the microstructure and mechanical properties of the processed region.

\section{Experimental}

The cast $\mathrm{CoCrFeNiCu}$ alloy sheets with $4.7 \mathrm{~mm}$ in thickness were used in this study. W-Re alloy with a shoulder diameter of $11 \mathrm{~mm}$ was adopted to process the $\mathrm{CoCrFeNiCu}$ alloy, and the FSP parameters with rotation rates of $200-500 \mathrm{rpm}$, travel speeds of $25-50 \mathrm{~mm} / \mathrm{min}$ and a tool tilt angle of $3^{\circ}$ were used. Besides, TiC-reinforced Ni-based ceramic welding tools with the shoulder diameter of $10 \mathrm{~mm}$ without rotation pin were adopted to process the $\mathrm{CoCrFeNiCu}$ alloy, and the FSP parameters with tool rotation rates of 200-600 rpm, tool traverse speeds of $25-50 \mathrm{~mm} / \mathrm{min}$ and tool tilt angles of $1.5^{\circ}$ and $3^{\circ}$ were used. The FSP of the $\mathrm{CoCrFeNiCu}$ alloy was conducted under the argon atmosphere to prevent oxidation and increase the cooling rate of the material. X-ray diffraction (XRD) using $\mathrm{Cu} K_{\mathrm{a}}$ radiation was used to acquire the lattice parameters and phase characteristics, and the XRD specimen size was $3 \mathrm{~mm} \times 3 \mathrm{~mm}$. The XRD investigation was performed with the diffraction angle $(2 \theta)$ from $30^{\circ}$ to $100^{\circ}$ at a speed of $2^{\circ} \mathrm{min}^{-1}$. The metallographic specimens were prepared perpendicular to the processing direction, cut using electric discharge machining and then were ground, polished and corroded with aquaregia. The metallographic structure was observed by Axio Observer Z1 research-type metallographic microscope. Scanning electron microscope (SEM, Supra 55) with energy-dispersive spectrometer (EDS, Oxford) was used to characterize microstructure and examine the element distribution. The detailed microstructure features were analyzed by electron back-scattered diffraction (EBSD, HKL) and transmission electron microscope (TEM, Tecnai $\mathrm{G}^{2} 20$ ). In order to eliminate spurious boundaries caused by orientation noise of EBSD, only the misorientation angle of more than $2^{\circ}$ was considered. Vickers hardness was measured by FM-700 microhardness tester with load of $200 \mathrm{~g}$ for $15 \mathrm{~s}$. Constant crosshead speed tensile tests were carried out on an Instron 5848 microtester at a strain rate of $10^{-3} \mathrm{~s}^{-1}$. The gauge length, width and thickness of the tensile specimen were $2.5 \mathrm{~mm}, 1.25 \mathrm{~mm}$ and $0.5 \mathrm{~mm}$, respectively. To ensure the experimental accuracy, two tensile specimens were prepared, and the schematic diagram of the tensile specimen taken from the processing area is shown in Fig. 1.

\section{Results and Discussion}

\subsection{Feasibility of FSP for the CoCrFeNiCu HEA}

As we know, W-Re alloy tool was a typical tool used for FSW/FSP of high melting temperature or high-strength 


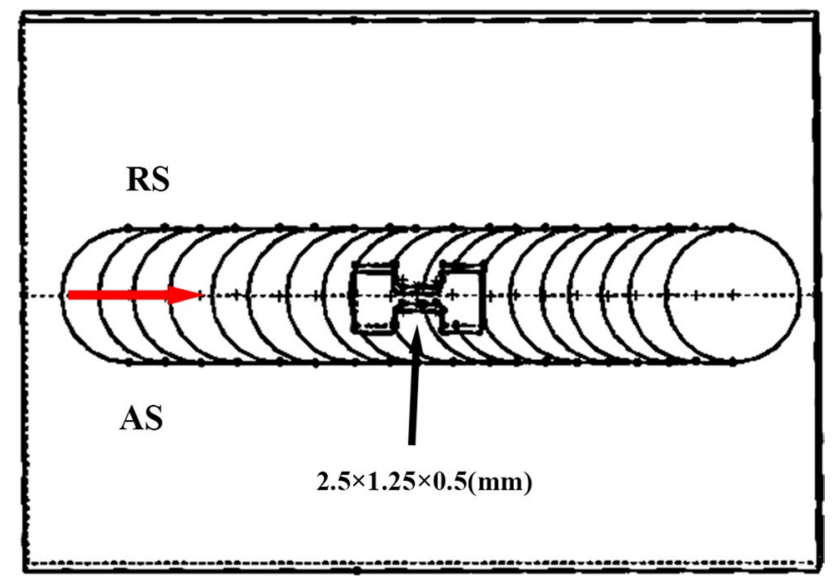

Fig. 1 Schematic diagram of processing area and tensile sample

metals [21, 22]. Considering the high melting point and high strength of the HEAs, we first explored the feasibility of FSP for the CoCrFeNiCu HEA using W-Re alloy tool under different parameters. Unfortunately, the $\mathrm{CoCrFeNiCu} \mathrm{HEA}$ could not be successfully processed by FSP, and defects were always formed. The typical FSP CoCrFeNiCu HEA area using a tool rotation rate of $500 \mathrm{rpm}$ and a tool traverse speed of $50 \mathrm{~mm} / \mathrm{min}$ is shown in Fig. 2a. For the W-Re alloy tool, there was a large friction coefficient and a good thermal conductivity, and thus it could produce a very large heat very fast and conducted the heat into the welded materials very quickly. When using the W-Re alloy tool, the heat could not be well controlled, and it was very easy to be overheated. Therefore, the CoCrFeNiCu HEA could not be successfully processed by FSP when using W-Re alloy tool.

To avoid the processing defect, we changed the tool to a Ni-based TiC-reinforced ceramic tool which has been proved to successfully achieve defect-free joints of $\mathrm{Ti}$ alloys and Al matrix composites [16, 17, 22]. However, it was found that the processing window for the $\mathrm{FSP}$ of the $\mathrm{CoCrFeNiCu}$ HEA was still very narrow, and it was very easy to form defects when using improper heat input. For example, when the FSPparameters with 550-600 rpm and $50 \mathrm{~mm} / \mathrm{min}$ were used, defects related to overheat were formed in the processed area; when the FSPparameters with 200-450 rpm and $25-50 \mathrm{~mm} / \mathrm{min}$ were used, defects related to insufficient material flow were formed in the processed area, with the typical example in Fig. 2b. It was mainly related to the fact that the material flow of $\mathrm{CoCrFeNiCu} \mathrm{HEA}$ was rather sensitive to the heat as the result of its viscous property and the heat sensitivity. When the material was overheated during the processing, the HEAs were too sticky to flow under the tool, leading to a deep tunnel formed in the processing area
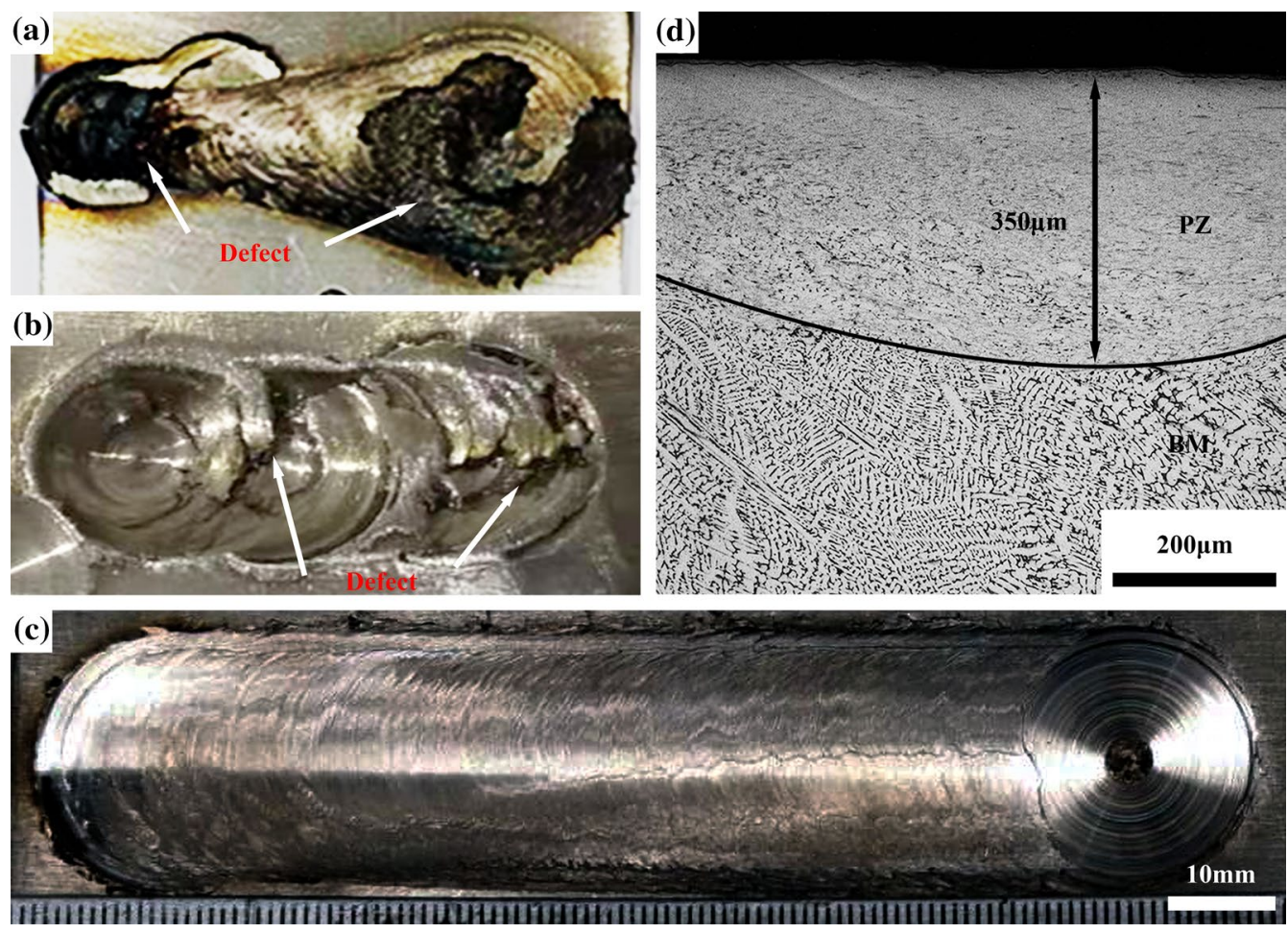

Fig. 2 a Typical processing surface with defects under a high heat input of $500 \mathrm{rpm}, 50 \mathrm{~mm} / \mathrm{min}$ using W-Re alloy tool, b typical processing surface with defects under an insufficient heat input of $300 \mathrm{rpm}, 50 \mathrm{~mm} / \mathrm{min}$ using TiC-reinforced Ni-based ceramic welding tool, c surface picture of the FSP plate without defects at $500 \mathrm{rpm}, 50 \mathrm{~mm} / \mathrm{min}$ using TiC-reinforced Ni-based ceramic welding tool, $\mathbf{d}$ cross-sectional structure of defect-free FSP zone of $\mathbf{c}$ 
(Fig. 2a). When the material temperature was too low during the processing, the HEAs were not softened enough, so that they could not flow or deform enough, resulting in obvious defects in the processing area (Fig. 2b).

Therefore, it was difficult to successfully achieve the defect-free FSP area of the as-cast $\mathrm{CoCrFeNiCu}$ alloy. Only when there was a proper heat input with $500 \mathrm{rpm}, 50 \mathrm{~mm} /$ min and a tool tilt angle of $1.5^{\circ}$, a defect-free processing joint was obtained, as shown in Fig. 2c. It was obvious that a smooth and shiny surface could be found in the processed region, because the argon gas was used during FSP to avoid surface oxidation. The cross section of the defect-free processing area is shown in Fig. 2d. The boundary of the processing region and other regions could be clearly identified, with a processing depth of about $350 \mu \mathrm{m}$. Besides, the base material (BM) showed very big grains, with obvious dendritic structure, and the average dendritic size was about $6 \mu \mathrm{m}$.

\subsection{Elimination of Cu Segregation After FSP}

Figure 3 illustrates the XRD results of as-cast and FSP $\mathrm{CoCrFeNiCu}$ alloys. Two FCC phases were found in the BM, named as FCC 1 phase and FCC 2 phase. Hsu et al. [36] reported that FCC 1 phase mainly composed of $\mathrm{Co}, \mathrm{Cr}$, Fe and Ni elements, and FCC 2 phase was mainly enriched by $\mathrm{Cu}$ at grain or dendrite boundaries in the as-cast $\mathrm{CoCr}$ $\mathrm{FeNiCu}$ alloy. FCC 2 phase should be the result of $\mathrm{Cu}$ element segregation in the cast dendrite boundaries. After FSP, the peak of $\mathrm{Cu}$-rich phase disappeared, and a single FCC phase was observed. This indicated that the $\mathrm{Cu}$ element segregation was probably eliminated by severe plastic deformation during FSP.

Figure 4 shows the SEM and EDS images of the BM and the PZ, respectively. The content of the $\mathrm{Cu}$ element at

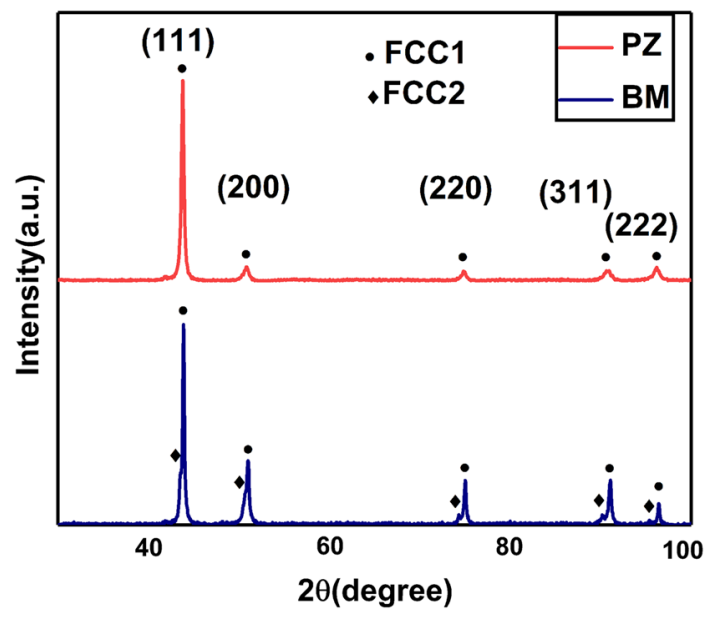

Fig. 3 XRD results of as-cast and FSP CoCrFeNiCu alloys the dendrite boundaries in the BM was much higher than that inside the grain (Fig. 4a), indicating that the $\mathrm{Cu}$ atoms of the BM were obviously concentrated at the boundaries between the dendrites. The reason should be attributed to two aspects. On the one hand, the melting point of $\mathrm{Cu}$ is the lowest compared to other four elements of $\mathrm{Co}, \mathrm{Cr}, \mathrm{Fe}$ and $\mathrm{Ni}$ in the as-cast $\mathrm{CoCrFeNiCu}$ alloy, and the solidification of the $\mathrm{Cu}$ element took place much later than other elements. Thus, during the solidification of the casting $\mathrm{CoCrFeNiCu}$ alloy, it was easier that the $\mathrm{Cu}$ element was concentrated at the dendrite boundary, resulting in the $\mathrm{Cu}$ segregation. On the other hand, it is well-known that from Gibbs free energy $\Delta G=\Delta H-\Delta T \cdot \Delta S$ (where $\Delta G$ is the Gibbs free energy, $\Delta H$ is the mixing enthalpy, $\Delta T$ is the temperature and $\Delta S$ is the mixing entropy), the smaller enthalpy and the larger entropy are benefit to reduce the Gibbs free energy, resulting in a more stable material.

Table 1 clearly shows that the mixing enthalpy of the four elements of $\mathrm{Co}, \mathrm{Cr}, \mathrm{Fe}$ and $\mathrm{Ni}$ was negative, and the mixing enthalpy between $\mathrm{Cu}$ and the other four elements was positive [37]. The smaller mixing enthalpy resulted in the lower Gibbs free energy and the more stable system. Therefore, it was easy for $\mathrm{Co}, \mathrm{Cr}, \mathrm{Fe}$ and $\mathrm{Ni}$ to form stable phase due to the lower free energy of the system. But for $\mathrm{Cu}$, it was more difficult to form stable phase with other elements due to the higher Gibbs free energy, and thus, it was very easy that the segregation of $\mathrm{Cu}$ occurred at the dendrite boundaries. For these two reasons, the $\mathrm{Cu}$ element in the as-cast $\mathrm{CoCr}$ $\mathrm{FeNiCu}$ alloy was segregated at the dendrite boundary.

But after FSP, the $\mathrm{Cu}$ segregation was almost eliminated (Fig. 4b). Due to the severe plastic deformation at high temperature during FSP, the $\mathrm{Cu}$ element enriched at the dendrite boundary was fast diffused into the grains and finally achieved a relatively homogeneous distribution. In this way, the element segregation almost disappeared after FSP. The result also agreed with the XRD results in Fig. 3.

\subsection{Strengthening of the CoCrFeNiCu HEA via FSP}

The hardness distribution through the processing region and the BM along the depth direction is shown in Fig. 5a. The hardness of the BM was about $150 \mathrm{HV}$. Along the depth direction from the bottom to the top, the hardness gradually increased, and reaching the PZ, it showed a much higher hardness with an average hardness value of $380 \mathrm{HV}$. Compared to the BM, the PZ increased the hardness by $>1.5$ times. It indicated that FSP largely increased the hardness of the cast $\mathrm{CoCrFeNiCu} \mathrm{HEA}$. The corresponding microstructures of the hardness points in the $\mathrm{BM}$, the $\mathrm{PZ}$ and the transition zone are shown in Fig. 5b-e. It was obvious that that the grain size gradually decreased form the BM to the PZ. Therefore, it was inferred that the grain refinement during 


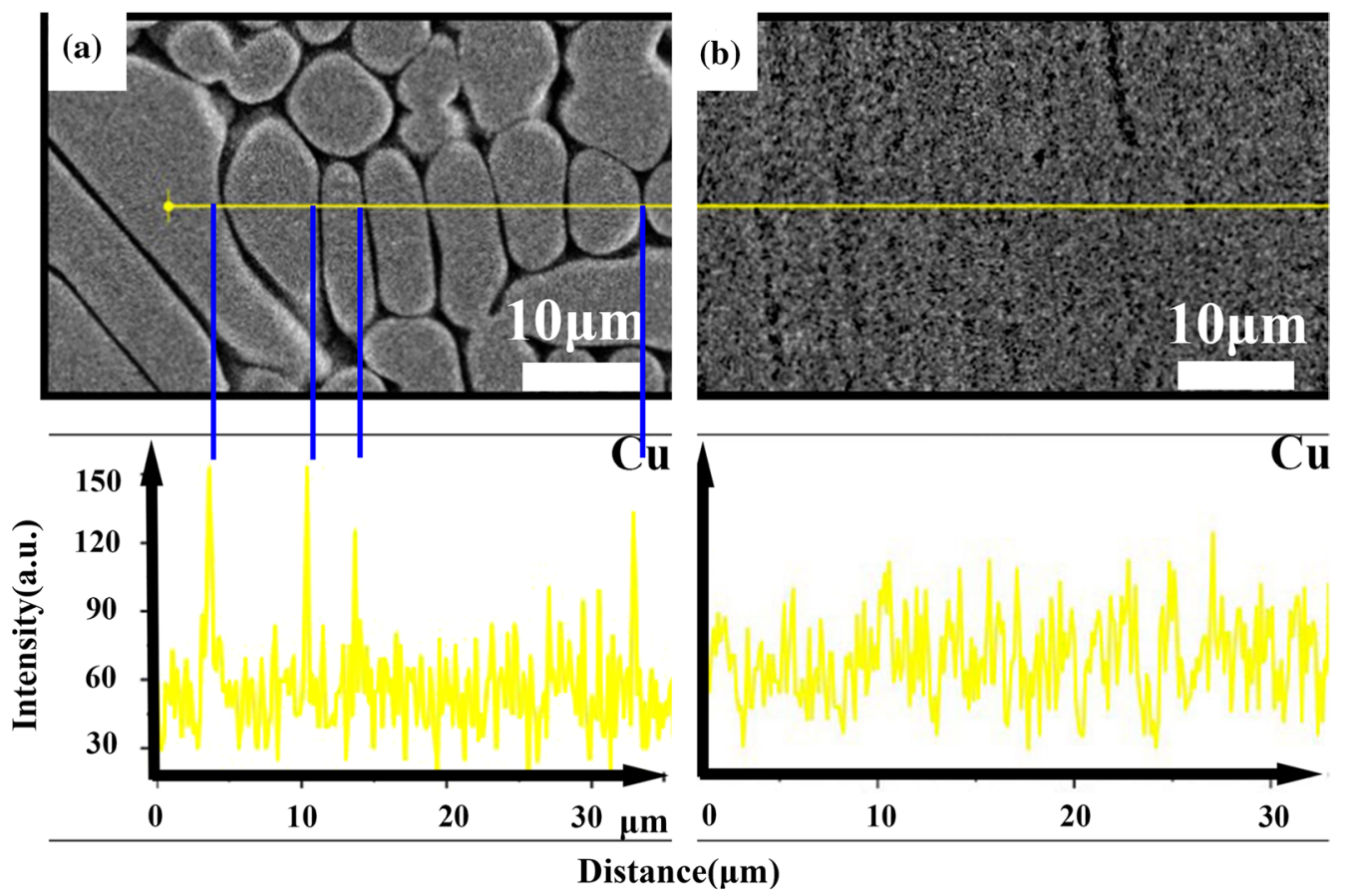

Fig. 4 SEM and EDS line scanning graphs of $\mathrm{Cu}$ element for $\mathrm{CoCrFeNiCu}$ alloy with different states: a as-cast and $\mathbf{b}$ FSP

Table 1 Chemical mixing enthalpy $\left(6 H^{\text {chem }}\right)$ of a pair of atoms [37]

\begin{tabular}{lllll}
\hline Element & $\mathrm{Co}$ & $\mathrm{Cr}$ & $\mathrm{Fe}$ & $\mathrm{Ni}$ \\
\hline $\mathrm{Cu}$ & 6 & 12 & 13 & 4 \\
$\mathrm{Co}$ & - & -4 & -1 & 0 \\
$\mathrm{Cr}$ & - & - & -1 & -7 \\
$\mathrm{Fe}$ & - & - & - & -2 \\
\hline
\end{tabular}

FSP might be an important reason for the increase in the hardness in the processing region.

The engineering stress-strain curves of the BM and the whole region including the FSPed zone and the BM are shown in Fig. 6. For the BM, the yield strength (YS) and tensile strength (UTS) were lower than 400 and $600 \mathrm{MPa}$, respectively. The elongation of the BM was about $28 \%$. After FSP, the whole processed region exhibited a much higher YS and UTS of over $1150 \mathrm{MPa}$. The whole processing region increased the YS even by $>1.5$ times than the cast BM, which suggested that FSP largely increased the HEA strength. But the ductility just decreased to about $5.2 \%$. Here, it should be pointed out that the whole FSP sample was used for tension in this study, just because the PZ was rather thin (no more than $0.35 \mu \mathrm{m}$ ), the accuracy of the tensile properties of the PZ might be affected if the
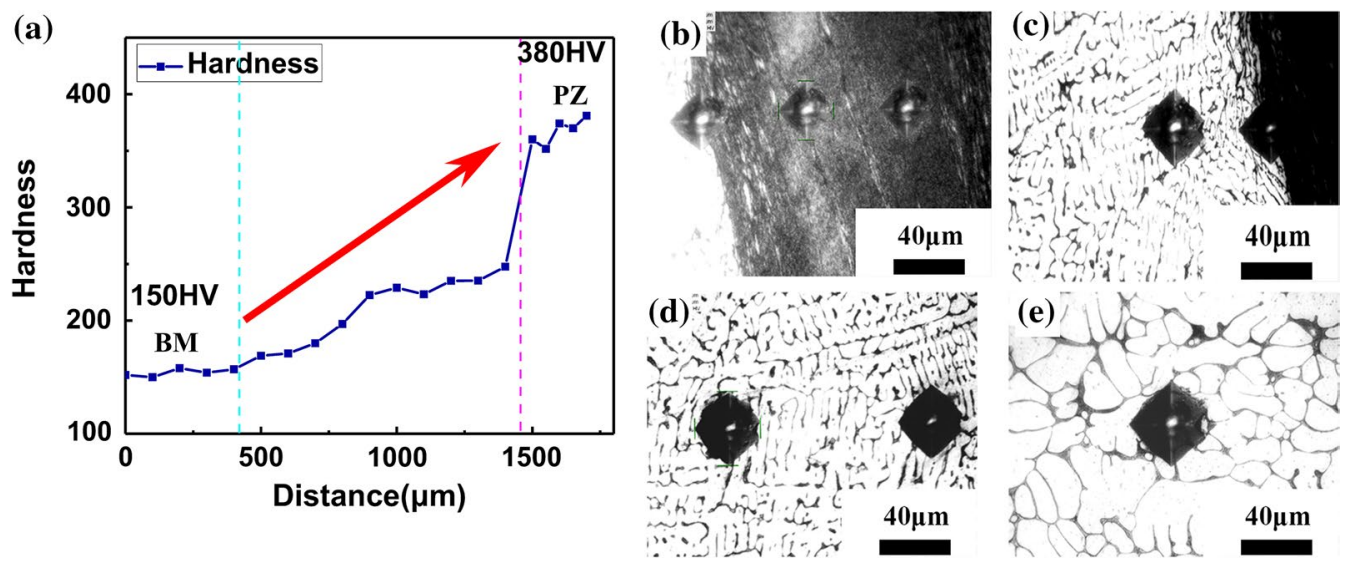

Fig. 5 a Hardness distribution along depth direction of FSP CoCrFeNiCu alloy, and its corresponding microstructure at different zones: b PZ, c, d transition zones, e BM 


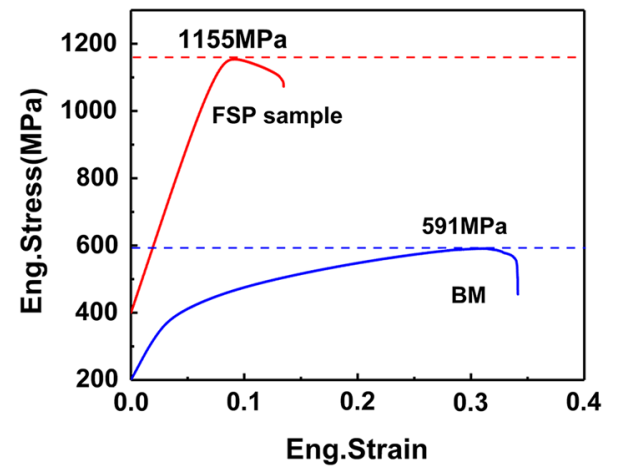

Fig. 6 Engineering stress-strain curves for BM and whole FSP samples

too-thin tensile sample only taken from the PZ was just used. Although the tensile property of the whole FSP sample could not exactly show that of the PZ, it could still reflect the strength of the PZ to some extent. The large strengthening of the whole FSP sample suggested that the strength of the PZ must be significantly enhanced.

The fracture surface morphologies of the BM and the whole FSP sample are shown in Fig. 7. For the BM, the large and deep dimples exhibited (Fig. 7c, e), indicating that the $\mathrm{BM}$ has a relatively good elongation. Compared with the BM, after FSP, the dimples of the PZ in Fig. 7d were obviously smaller and shallower. Therefore, the elongation of the whole region was lower than that of the BM. The high elongation of the BM was mainly because the coarse grain can store more dislocations, which had stronger workhardening ability. After FSP, the grains were largely refined into ultrafine ones. This ultrafine-grained structure usually exhibited a poor work-hardening ability, which resulted in a quick necking, and a low ductility exhibited $[10,11]$.

\subsection{Ultrafine-Grained Microstructure Obtained by FSP}

In order to explain the strengthening phenomenon, the detailed microstructure after FSP was observed, as shown in Figs. 8 and 9. Figure 8a, b shows the EBSD map and the misorientation angle distribution of the $\mathrm{CoCrFeNiCu} \mathrm{BM}$. It was obvious that the BM showed a large grain size, and the fraction of the high-angle grain boundaries (HAGBs) was about $73.3 \%$. After FSP, the PZ exhibited an ultrafine or even nano-equiaxed recrystallized structure with relatively uniform grain distribution (Fig. 8c). Calculated by EBSD analysis software, the average grain size of PZ was
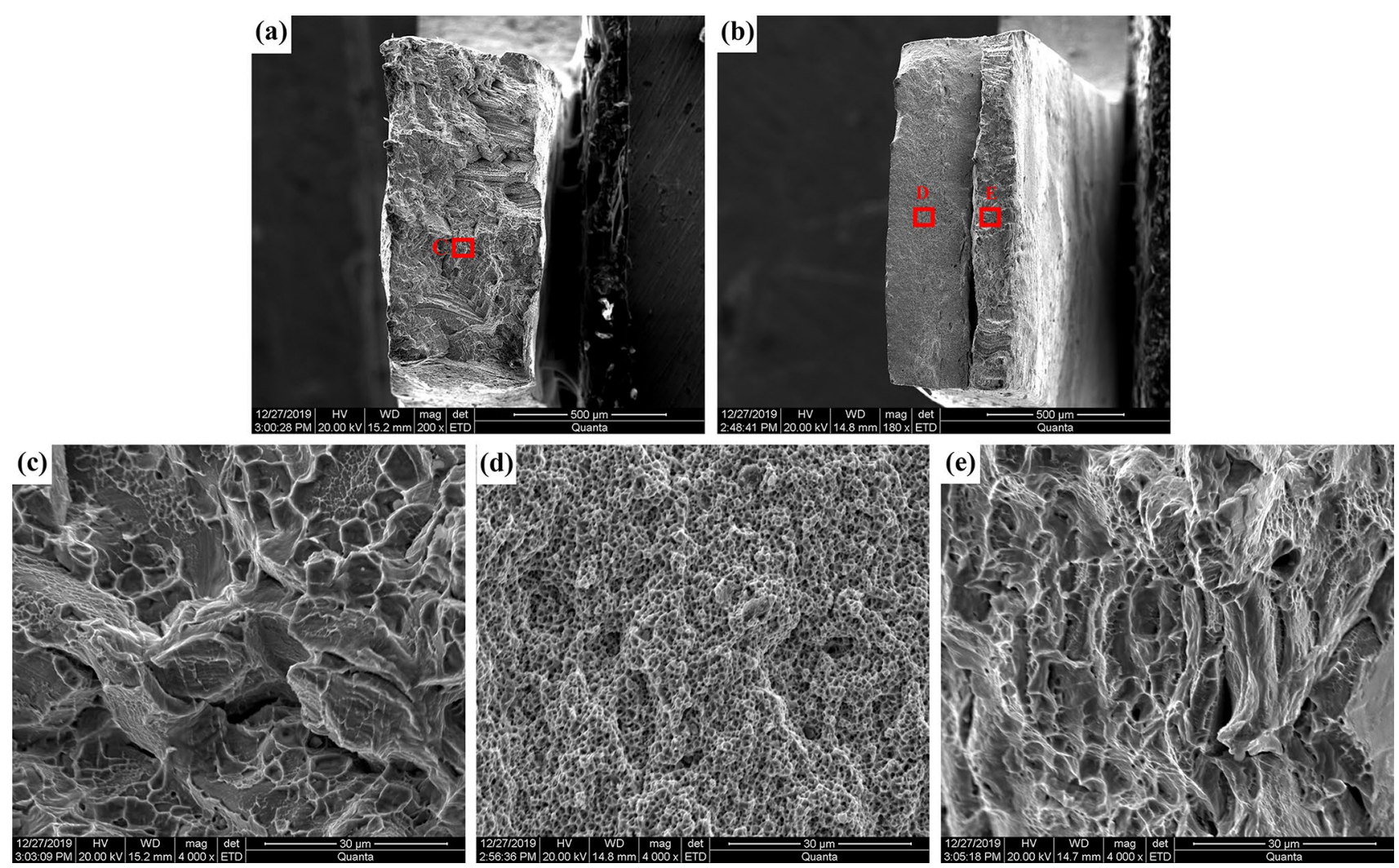

Fig. 7 a, b Macrographs of fracture surfaces of BM and FSP samples, $\mathbf{c}-\mathbf{e}$ magnified images of fracture surfaces corresponding to positions C, D and $E$ in $\mathbf{a}$ and $\mathbf{b}$ 

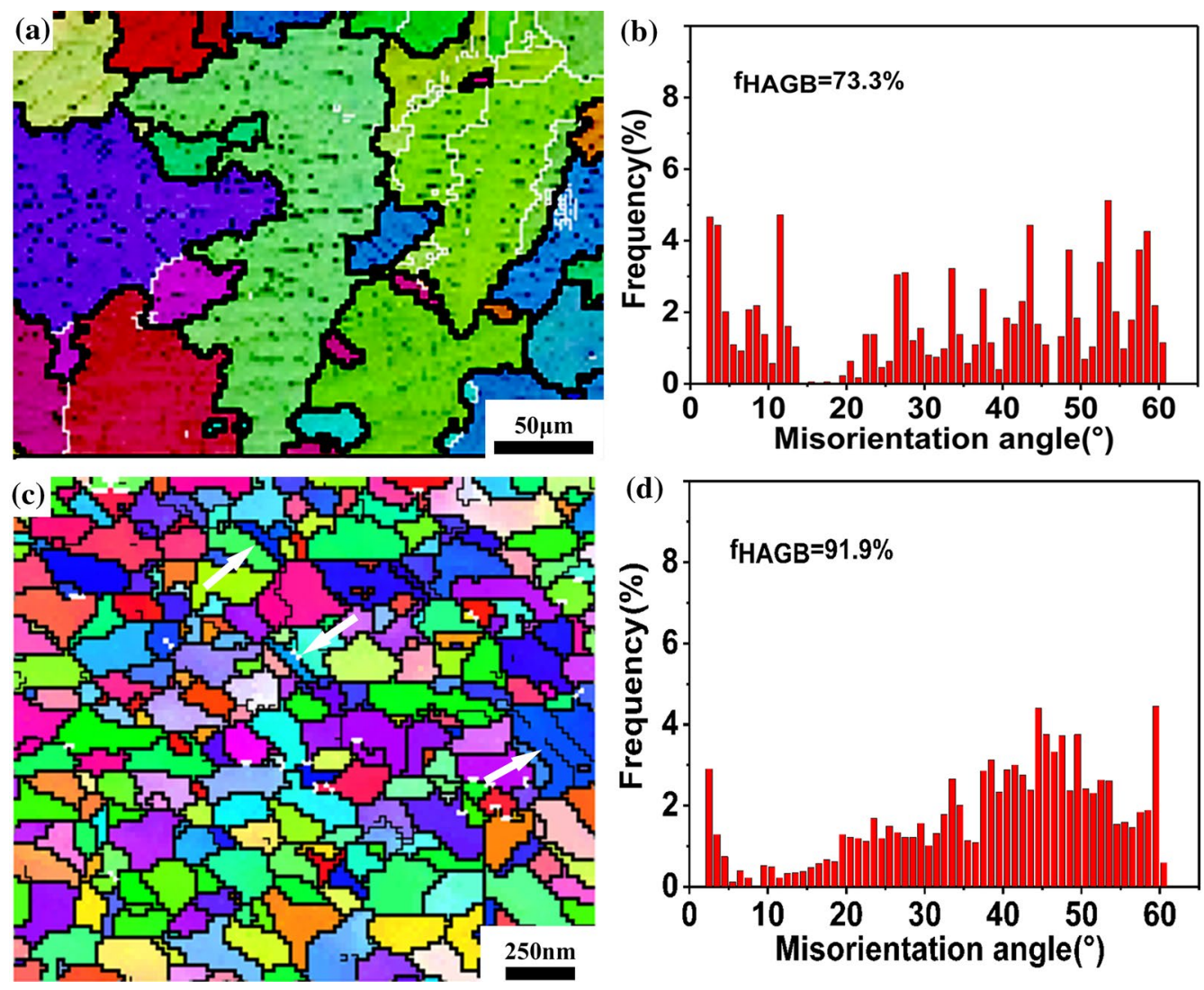

Fig. 8 a, $\mathbf{c}$ EBSD maps of BM and PZ of FSP CoCrFeNiCu alloy, b, $\mathbf{d}$ their corresponding distributions of misorientation angle

determined to be $80 \mathrm{~nm}$, that is to say, the PZ consisted of a nano-grained structure. However, this statistic grain size might be not exact limited by the EBSD resolution, and the grain sizes are subsequently measured by TEM, which was determined to be $150 \mathrm{~nm}$ (Fig. 9, which will be analyzed later).

Figure 8d shows the misorientation angle distribution of the PZ. It was found that the PZ contained a high fraction of HAGBs of about $91.9 \%$ (HAGB cutoff angle of $15^{\circ}$ ), which should be the result of dynamic recrystallization. As we know, discontinuous dynamic recrystallization is generally easier to take place in the metals with low stacking fault energy (SFE). It was reported that $\mathrm{CoCrFeNiCu}$ alloy was found to have low SFE [38], so the recrystallization process during FSP of CoCrFeNiCu alloy may be mainly associated with discontinuous dynamic recrystallization. Also, it is generally easier to obtain a high fraction of HAGB over 90\% when discontinuous dynamic recrystallization dominates while a range of $60-80 \%$ HAGBs generally exhibits when continuous dynamic recrystallization dominates [19]. The existence of over 90\% HAGBs in the PZ further suggested that the grain refinement during FSP might be related to discontinuous dynamic recrystallization. Besides, there was a small misorientation angle peak near $60^{\circ}$ (Fig. 8d).
As we know, when the special misorientation angle of the boundaries appears around $60^{\circ}$, these special boundaries are generally the $\{111\}$ twin boundaries, and the typical twin boundaries are marked by white arrows in Fig. 8c. Unfortunately, limited by the accuracy of EBSD, the nano-twins could not be accurately obtained by EBSD analysis, which will be reflected by the TEM.

The TEM images of the PZ are shown in Fig. 9. Many nano-sized grains with a low dislocation density were detected in the PZ (Fig. 9a), which might be a main reason for the significant increase in the hardness and strength in the PZ. In addition, a part of twin-crystal structures was found in the ultrafine grains. Figure $9 \mathrm{c}$ shows the detailed twin feature in a complete grain in the PZ, and the nanoscale twins in the PZ can be clearly observed. There were different contrasts between A region, B region and $\mathrm{C}$ region in the grain (Fig. 9c), whose selected area electron diffraction (SAD) is shown in Fig. 9d. The SAD pattern showed that different from the traditional set of twin spots, two sets of twin spots can be found in Fig. 9d. In Fig. 9d, the SAD of the A and B regions was set as a set of twin spot with matrix and primary twin, and that of the $\mathrm{B}$ and $\mathrm{C}$ regions was another set of twin spots with primary twin and secondary twin. Thus, the A region was 

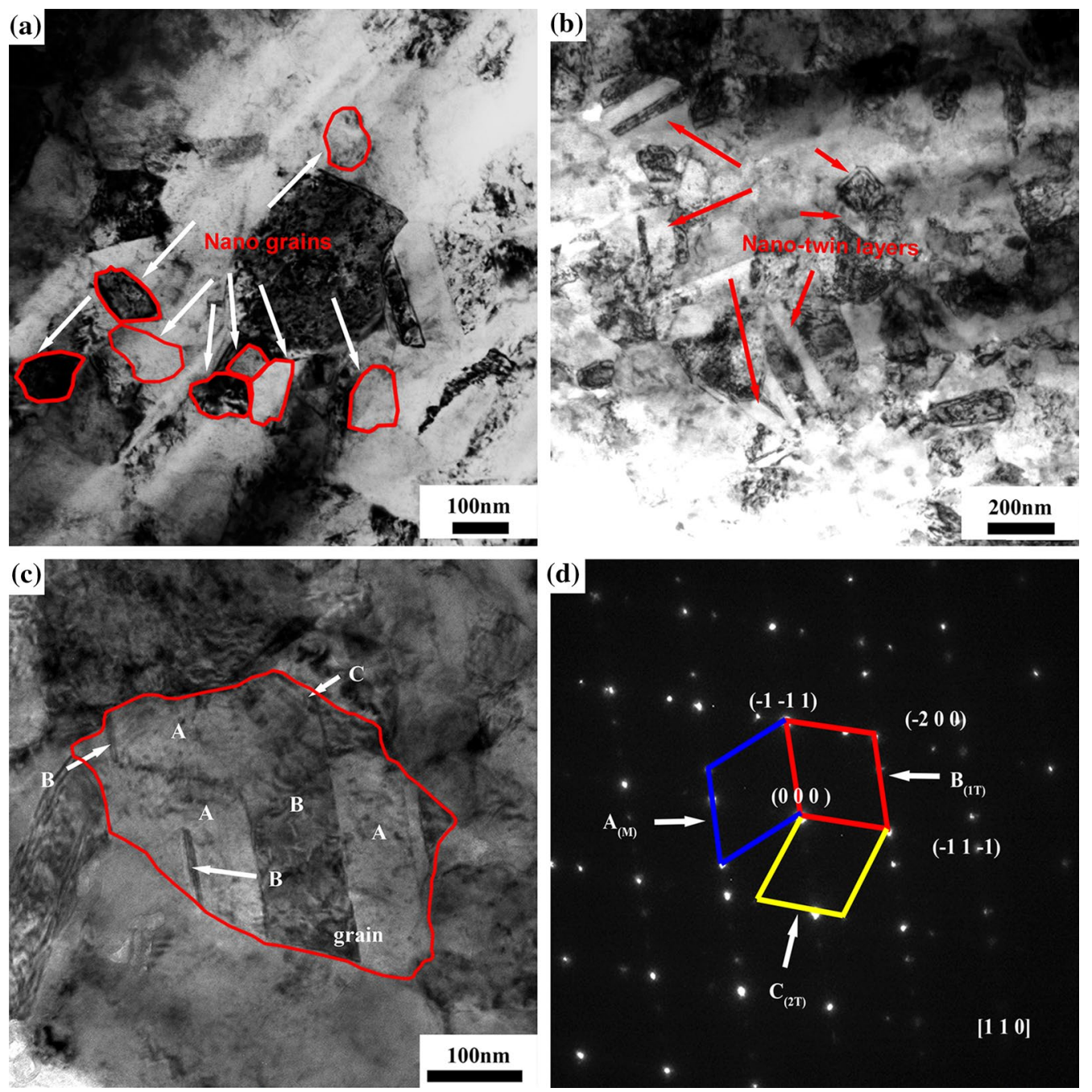

Fig. 9 TEM microstructures of FSP CoCrFeNiCu alloy: a nano-grains, $\mathbf{b}$ nano-twins within grains, $\mathbf{c}$ detailed nano-twins, $\mathbf{d}$ SAD pattern of nano-twins

the material matrix, and the B region was the primary twin formed during the deformation process. The $\mathrm{C}$ region was the secondary deformation twin in the $\mathrm{B}$ region. The existence of nano-deformation twins should be also one of the important reasons for the large improvement in the hardness and strength.

As we know, a lower temperature, higher strain rate and low SFE are benefit for the formation of twins [19]. Zaddach et al. [38] calculated that the SFE of NiFeCoCr HEA is very low, only $17 \mathrm{~mJ} / \mathrm{m}^{2}$. Twin structures were also observed in the CoCrFeNiMn HEA [39] and $\mathrm{Al}_{0.1} \mathrm{CoCrFeNi}$ HEA [40] after SPD. Thus, the low SFE of the HEA was benefit for the formation of the twins in this study. In addition, the strain rate during FSP was very large, generally reaching an order of $10 \mathrm{~s}^{-1}$ [14]. Furthermore, due to the pin-free tool used in the FSP, the deformation temperature is relatively low and the processing region could be cooled down quickly. Thus, nano-deformation twins were observed in $\mathrm{CoCrFeNiCu}$ alloy after FSP (Fig. 9b).

For comparison, the grain size information of different HEAs obtained by FSW/FSP from the previous literature and this study is summarized in Table $2[29,30,32,33,41$, 42]. It was obvious that a micro-scale-grained structure was obtained in most of the previous literature on FSW/FSP of as-cast HEAs. While in this study, the grain size of $\mathrm{CoCr}$ $\mathrm{FeNiCu}$ after FSP was only $150 \mathrm{~nm}$, which was the smallest grain size in the literature on FSW/FSP of the cast HEAs ever reported. This might be related to the fact that a larger grain refinement was achieved by the welding tool with no pin due to the more rapid cooling rate.

Actually, the ultrafine-grained structure in this study was an extremely fine microstructure, and in the previous papers on the FSP of the conventional alloys [14, 17], such an ultrafine-grained microstructure was almost impossible to 
Table 2 Grain sizes of different HEAs after FSW/FSP

\begin{tabular}{lll}
\hline Materials & Grain size $(\mu \mathrm{m})$ & References \\
\hline $\mathrm{Al}_{0.1} \mathrm{CoCrFeNi}$ & 0.35 & {$[30]$} \\
$\mathrm{Al}_{0.3} \mathrm{CoCrFeNi}$ & 2.66 & {$[32]$} \\
$\mathrm{Co}_{16} \mathrm{Fe}_{28} \mathrm{Ni}_{28} \mathrm{Cr}_{28}$ & 1.29 & {$[33]$} \\
$\mathrm{Fe}_{50} \mathrm{Mn}_{30} \mathrm{Co}_{10} \mathrm{Cr}_{10}$ & 6.5 & {$[29]$} \\
$\mathrm{Fe}_{42} \mathrm{Mn}_{28} \mathrm{Co}_{10} \mathrm{Cr}_{15} \mathrm{Si}_{5}$ & 1.3 & {$[41]$} \\
$\mathrm{CoCrFeNiMn}$ & 2 & {$[42]$} \\
$\mathrm{CoCrFeNiCu}$ & 0.15 & This study \\
\hline
\end{tabular}

be obtained in air, which usually needed an additional cooling operation such as FSP under liquid $\mathrm{N}_{2}$, water or other coolants. Thus, the production of the ultrafine microstructure in this study might be also attributed to the HEAs own characteristics besides the severe plastic deformation during FSP. Different from traditional alloys, HEAs have the sluggish diffusion effect in dynamics and the lattice distortion effect in crystallography. From the viewpoint of dynamics, the sluggish diffusion effect will increase the recrystallization temperature of the HEAs during hot deformation, thereby reducing the grain growth rate after FSP and obtaining finer grain structure.

Zhou et al. [43] studied the grain growth of the CoCrFeMnNi HEA alloy at the cold rolling and annealed state. It was found that the activation energy of the HEA alloy was much higher than that of AISI301LN stainless steel. It was obvious that from the viewpoint of energy, the severe lattice distortion in the HEAs led to the diffusion of atoms in the recrystallization process that required greater activation energy. Thus, the diffusion coefficient of the HEAs was reduced, resulting in the HEA grains more difficult to grow than that of the conventional alloys. As a result, the recrystallized grains of the $\mathrm{CoCrFeNiCu}$ HEA were not easily grown after FSP. Therefore, in this study, compared to that of the conventional alloys, a much smaller grain size of the $\mathrm{CoCrFeNiCu}$ alloy was produced after FSP.

From the analysis above, some interesting results were obtained in this study. It was feasible for FSP applied to the $\mathrm{CoCrFeNiCu} \mathrm{HEA}$, and an ultrafine-grained structure with a high fraction of HAGBs could be produced during FSP, which was the result of the severe plastic deformation during FSP and the sluggish effect and severe lattice distortion of the HEA itself. Nano-twins were found in the grains mainly because of the low SFE of $\mathrm{CoCrFeNiCu}$ HEA and high strain rate with a relatively low heat input during FSP. Besides, the significant grain refinement after FSP coupled with lattice distortion was the most important mechanism for the significant hardness and strength improvement, since the movement of dislocation was greatly hindered by the ultrafine crystal structure with a severe lattice distortion in the PZ [44]. In addition, the nano-twins also contributed to the strengthening in the PZ [45].

It should be pointed out that it was interesting that such a high fraction (about 92\%) of HAGBs in such fine grains was found. It was totally different from those ultrafine or nano-grains obtained by other SPD methods, which generally contained low-angle grain boundaries and too many dislocations. The previous papers on the fine- or ultrafinegrained structure with high fractions of HAGBs in conventional alloys via FSP have shown the particularly excellent properties, such as superplasticity and fatigue properties $[46,47]$. In the FSP ultrafine-grained HEAs, a particular superplasticity, fatigue property or other properties might be expected, which will be further reported in our following studies.

\section{Conclusions}

In this study, the feasibility of the FSP for the $\mathrm{CoCrFeNiCu}$ HEA was explored for the first time, and the detailed microstructure and mechanical properties were studied. The conclusions were as follows.

(1) A defect-free processed zone of $\mathrm{CoCrFeNiCu}$ alloy was successfully achieved.

(2) FSP almost eliminated the $\mathrm{Cu}$ element segregation. The PZ exhibited an ultrafine-equiaxed recrystallization structure with a high fraction of HAGBs and nanoscale twins.

(3) An ultrafine-grained structure was the result of the severe plastic deformation during FSP and the sluggish effect and lattice distortion of the HEA itself. The formation of nano-twins was mainly related to the low SFE of $\mathrm{CoCrFeNiCu}$ HEA and high strain rate with a relatively low heat input during FSP.

(4) FSP largely improved the $\mathrm{CoCrFeNiCu} \mathrm{HEA}$, and the PZ exhibited a much higher hardness and yield strength with the increase of $>1.5$ times compared with the BM. The significant strength increase was mainly attributed to the large grain refinement with severe lattice distortion and the formation of nano-twins.

Acknowledgements This work was supported by the National Natural Science Foundation of China under Grant Nos. 51601194, 51975553, 51575362 and the IMR SYNL-T.S. Kê Research Fellowship.

\section{References}

[1] C.W. Tsai, M.H. Tsai, J.W. Yeh, C.C. Yang, J. Alloys Compd. 490, 160 (2010) 
[2] H. Zhang, Y. Pan, Y.Z. He, J.L. Wu, T.M. Yue, S. Guo, JOM 66, 2057 (2014)

[3] B. Gludovatz, A. Hohenwarter, D. Catoor, E.H. Chang, E.P. George, R.O. Ritchie, Science 345, 1153 (2014)

[4] M.A. Hemphill, T. Yuan, G.Y. Wang, J.W. Yeh, C.W. Tsai, A. Chuang, P.K. Liaw, Acta Mater. 60, 5723 (2012)

[5] O.N. Senkov, J.M. Scott, Scr. Mater. 50, 449 (2004)

[6] S.L. Gibbons, R.A. Abrahams, M.W. Vaughan, R.E. Barber, R.C. Harris, R. Arroyave, I. Karaman, Mater. Sci. Eng. A 725, 57 (2018)

[7] A.V. Podolskiy, Y.O. Shapovalov, E.D. Tabachnikova, A.S. Tortika, M.A. Tikhonovsky, B. Joni, E. Odor, T. Ungar, S. Maier, C. Rentenberger, M.J. Zehetbauer, E. Schafler, Adv. Eng. Mater. 22, 1900752 (2020)

[8] W.J. Kim, H.T. Jeong, H.K. Park, K. Park, T.W. Na, E. Choi, J. Alloys Compd. 802, 152 (2019)

[9] N. Tao, K. Lu, J. Mater. Sci. Technol. 23, 771 (2007)

[10] R. Valiev, Nat. Mater. 3, 511 (2004)

[11] Y.T. Zhu, X.Z. Liao, Nat. Mater. 3, 351 (2004)

[12] I. Charit, R.S. Mishra, M.W. Mahoney, Scr. Mater. 47, 631 (2002)

[13] F.C. Liu, Z.Y. Ma, Metall. Mater. Trans. A 39, 2378 (2008)

[14] R.S. Mishra, Z.Y. Ma, Mater. Sci. Eng., R 50, 1 (2005)

[15] G.R. Cui, Z.Y. Ma, S.X. Li, Acta Mater. 57, 5718 (2009)

[16] A.H. Feng, B.L. Xiao, Z.Y. Ma, Compos. Sci. Technol. 68, 2141 (2008)

[17] P. Xue, X.X. Zhang, L.H. Wu, Z.Y. Ma, Acta Metall. Sin. 52, 1222 (2016). (in Chinese)

[18] X.H. Zeng, P. Xue, L.H. Wu, D.R. Ni, B.L. Xiao, Z.Y. Ma, Mater Sci. Eng. A 755, 28 (2019)

[19] L.H. Wu, X.B. Hu, X.X. Zhang, Y.Z. Li, Z.Y. Ma, X.L. Ma, B.L. Xiao, Acta Mater. 166, 371 (2019)

[20] H. Zhang, D. Wang, P. Xue, L.H. Wu, D.R. Ni, B.L. Xiao, Z.Y. Ma, J. Mater. Sci. Technol. 34, 2183 (2018)

[21] L.H. Wu, D. Wang, B.L. Xiao, Z.Y. Ma, Scr. Mater. 78-79, 17 (2014)

[22] L.H. Wu, H. Zhang, X.H. Zeng, P. Xue, B.L. Xiao, Z.Y. Ma, Sci. China Mater. 61, 417 (2018)

[23] G. Chen, S. Zhang, Y. Zhu, C. Yang, Q. Shi, Acta Metall. Sin. -Engl. Lett. 33, 3 (2020)

[24] B. He, L. Cui, D.P. Wang, H.J. Li, C.X. Liu, Acta Metall. Sin. -Engl. Lett. 33, 135 (2020)

[25] W. Wang, P. Han, P. Peng, T. Zhang, Q. Liu, S.N. Yuan, L.Y. Huang, H.L. Yu, K. Qiao, K.S. Wang, Acta Metall. Sin. -Engl. Lett. 33, 43 (2020)
[26] F. Bakhtiari Argesi, A. Shamsipur, S.E. Mirsalehi, Acta Metall. Sin. -Engl. Lett. 31, 1183 (2018)

[27] A.H. Feng, D.L. Chen, Z.Y. Ma, W.Y. Ma, R.J. Song, Acta Metall. Sin. -Engl. Lett. 27, 723 (2014)

[28] D. Wang, B.L. Xiao, D.R. Ni, Z.Y. Ma, Acta Metall. Sin. -Engl. Lett. 27, 816 (2014)

[29] S.S. Nene, K. Liu, M. Frank, R.S. Mishra, R.E. Brennan, K.C. Cho, Z. Li, D. Raabe, Sci. Rep. 7, 16167 (2017)

[30] M. Komarasamy, N. Kumar, Z. Tang, R.S. Mishra, P.K. Liaw, Mater. Res. Lett. 3, 30 (2015)

[31] G.R. Argade, N. Kumar, R.S. Mishra, Mater. Sci. Eng. A 565, 80 (2013)

[32] Z.G. Zhu, Y.F. Sun, M.H. Goh, F.L. Ng, Q.B. Nguyen, H. Fujii, S.M.L. Nai, J. Wei, C.H. Shek, Mater. Lett. 205, 142 (2017)

[33] Z.G. Zhu, Y.F. Sun, F.L. Ng, M.H. Goh, P.K. Liaw, H. Fujii, Q.B. Nguyen, Y. Xu, C.H. Shek, S.M.L. Nai, J. Wei, Mater. Sci. Eng. A 711, 524 (2018)

[34] S.M. Oh, S.I. Hong, Key Eng. Mater. 765, 149 (2018)

[35] H. Zhang, Y.Z. He, Y. Pan, S. Guo, J. Alloys Compd. 600, 210 (2014)

[36] Y.J. Hsu, W.C. Chiang, J.K. Wu, Mater. Chem. Phys. 92, 112 (2005)

[37] A. Takeuchi, A. Inoue, Mater. Trans. JIM 41, 1372 (2000)

[38] A.J. Zaddach, C. Niu, C.C. Koch, D.L. Irving, JOM 65, 1780 (2013)

[39] N. Stepanov, M. Tikhonovsky, N. Yurchenko, D. Zyabkin, M. Klimova, S. Zherebtsov, A. Efimov, G. Salishchev, Intermetallics 59, 8 (2015)

[40] N. Kumar, M. Komarasamy, P. Nelaturu, Z. Tang, P.K. Liaw, R.S. Mishra, JOM 67, 1007 (2015)

[41] S.S. Nene, M. Frank, K. Liu, R.S. Mishra, B.A. McWilliams, K.C. Cho, Sci. Rep. 8, 9920 (2018)

[42] D. Shaysultanov, N. Stepanov, S. Malopheyev, I. Vysotskiy, V. Sanin, S. Mironov, R. Kaibyshev, G. Salishchev, S. Zherebtsov, Mater. Charact. 145, 353 (2018)

[43] W. Zhou, L.M. Fu, P. Liu, X.D. Xu, B. Chen, G.Z. Zhu, X.D. Wang, A.D. Shan, M.W. Chen, Intermetallics 85, 90 (2017)

[44] S. Yoshida, T. Bhattacharjee, Y. Bai, N. Tsuji, Scr. Mater. 134, 33 (2017)

[45] L. Lu, X. Chen, X. Huang, K. Lu, Science 323, 607 (2009)

[46] P. Xue, B.B. Wang, X.H. An, D.R. Ni, B.L. Xiao, Z.Y. Ma, Scr. Mater. 166, 10 (2019)

[47] F.C. Liu, Z.Y. Ma, Scr. Mater. 62, 125 (2010) 